\title{
Gestational Weight Gain Particularly Affects the Risk of Large for Gestational Age Infants in Non-obese Mothers
}

\author{
Gewichtszunahme in der Schwangerschaft beeinflusst \\ das Risiko besonders von nicht adipösen Müttern, \\ hypertrophe Neugeborene zu gebären
}

(C) (9) $\ominus$

Authors

Friederike Weschenfelder ${ }^{1}$, Thomas Lehmann ${ }^{2}$, Ekkehard Schleussner ${ }^{1}$, Tanja Groten ${ }^{1}$

Affiliations

1 University Hospital Jena, Department of Obstetrics, Jena, Germany

2 Institute of Medical Statistics and Computer Science, University Hospital Jena, Friedrich Schiller University Jena, Jena, Germany

Key words

pregnancy, diabetes mellitus, obesity, weight gain, large for gestational age, gestational diabetes

Schlüsselwörter

Schwangerschaft, Diabetes mellitus, Adipositas, Gewichtszunahme, Large-for-gestational-age, Gestationsdiabetes

received 23.11.2018

revised 21.3.2019

accepted 6.4.2019

Bibliography

DOI https://doi.org/10.1055/a-0891-0919

Published online 3. 9. 2019 | Geburtsh Frauenheilk 2019; 79: 1183-1190 @ Georg Thieme Verlag KG Stuttgart · New York | ISSN 0016-5751

Correspondence

Dr. Friederike Weschenfelder

University Hospital Jena, Department of Obstetrics

Am Klinikum 1, 07747 Jena, Germany

Friederike.Weschenfelder@med.uni-jena.de

\section{ABSTRACT}

Introduction The birth of a large for gestational age (LGA) infant is a significant risk factor for birth complications and maternal morbidity and an even higher risk factor for offspring obesity, metabolic syndrome and cardiovascular disease in later life. Relevant factors affecting the risk of delivering an LGA infant are maternal pre-gravid obesity, excessive gesta- tional weight gain exceeding the recommendations of the Institute of Medicine (IOM) and diabetes in pregnancy. We aimed to determine what matters most in terms of the risk of fetal overgrowth.

Materials and Methods We performed a database analysis of 12701 singleton term deliveries documented in our university hospital birth registry from 2003 to 2014. Multivariate logistic regression analysis was used to determine the adjusted odds ratios.

Results Excessive weight gain had the strongest impact on LGA (OR: 1.249 [95\% Cl: 1.018-1.533]) compared to maternal pre-gravid body mass index (BMI) (OR: 1.083 [95\% Cl: 1.066-1.099]) and diabetes (OR: 1.315 [95\% Cl: 0.9971.734]). Keeping gestational weight gain within the recommendations of the IOM resulted in a risk reduction for LGA of 20\% (OR: 0.801 [95\% Cl: 0.652-0.982]). The risk for LGA increases by $6.9 \%$ with each $\mathrm{kg}$ weight gain. Normal weight women (BMI $18.5-24.9 \mathrm{~kg} / \mathrm{m}^{2}$ ) and moderately overweight women (BMI $25-29.9 \mathrm{~kg} / \mathrm{m}^{2}$ ) showed the highest increase in LGA rates per $\mathrm{kg}$ weight gain during pregnancy (OR: 1.078 [95\% Cl: 1.052-1.104] and OR: 1.058 [95\% Cl: 1.026-1.09], resp.). Only in underweight ( $\left.<18.5 \mathrm{~kg} / \mathrm{m}^{2}\right)$ and normal weight women the risk of LGA birth is strongly influenced by diabetes (OR 11.818 [95\% Cl: 1.156-120.782] and 1.564 [95\% Cl: 1.013-2.415]).

Conclusion Excessive weight gain is particularly important for non-obese women. These women are therefore a target cohort for intervention, as each prevented additional kilogram weight gain reduces the risk of LGA by more than $5 \%$.

\section{ZUSAMMENFASSUNG}

Einleitung Die Geburt eines hypertrophen Neugeborenen, auch Large-for-gestational-age (LGA) genannt, stellt einen signifikanten Risikofaktor für Geburtskomplikationen sowie mütterliche Morbidität sowie einen noch höheren Risikofaktor für Übergewichtigkeit, metabolisches Syndrom und HerzKreislauf-Erkrankungen des Nachwuchses im späteren Leben dar. Die wichtigsten Faktoren, die sich auf das LGA-Risiko aus- 
wirken, sind Adipositas vor der Schwangerschaft, eine exzessive Gewichtszunahme in der Schwangerschaft, welche die Empfehlungen des Institute of Medicine (IOM) übersteigt, sowie ein Schwangerschaftsdiabetes. Ziel dieser Studie war es, herauszufinden, welche Faktoren die größte Auswirkung auf das Risiko für LGA haben.

Material und Methoden Wir führten eine Datenbankanalyse von 12701 Termingeburten durch, die zwischen 2003 und 2014 im Geburtenregister unseres Universitätskrankenhauses dokumentiert wurden. Eine multivariate logistische Regressionsanalyse wurde durchgeführt, um die adjustierten Quotenverhältnissen (Odds Ratios, ORs) zu ermitteln.

Ergebnisse Es stellte sich heraus, dass eine exzessive Gewichstzunahme die größte Auswirkung auf das Risiko für LGA hatte (OR 1,249 [95\%-KI 1,018-1,533]), verglichen mit mütterlichem Body-Mass-Index (BMI) vor der Schwangerschaft (OR 1,083 [95\%-KI 1,066-1,099]) und Diabetes (OR 1,315 [95\%-KI 0,997-1,734]). Gelang es, die Gewichtszunahme in der Schwangerschaft innerhalb des von der IOM empfohlenen Rahmens zu halten, reduzierte sich das Risiko für LGA um 20\% (OR 0,801 [95\%-KI 0,652-0,982]). Das Risiko für LGA nahm mit jedem zusätzlichen Kilo an Gewicht um 6,9\% zu. Die höchsten Zunahmen an LGA-Raten pro zusätzlichem Kilo Gewichtszunahme in der Schwangerschaft wurden bei normalgewichtigen (BMI 18,5-24,9 kg/m²) und etwas übergewichtigen Frauen (BMI 25-29,9 kg/m²) verzeichnet (OR 1,078 [95\%KI 1,052-1,104] bzw. OR 1,058 [95\%-KI 1,026-1,09]). Nur bei untergewichtigen und normalgewichtigen Frauen zeigte der Diabetes einen signifikanten Einfluss auf das LGA-Risiko (OR 11,818 [95\%-KI: 1,156-120,782] und 1,564 [95\%-KI: 1,0132,415]).

Schlussfolgerung Die Folgen der exzessiven Gewichtszunahme wirken sich besonders stark bei nicht adipösen Frauen aus. Diese Frauen stellen daher eine Zielkohorte für Interventionen dar, da jedes verhinderte zusätzliche Kilo an Gewicht das Risiko für LGA um mehr als $5 \%$ reduziert.

\section{Introduction}

Being overweight or obese are major risk factors for cardiovascular disease, diabetes, musculoskeletal disorders and some cancers. Today, overweight and obesity are linked to more deaths worldwide than underweight. Childhood obesity has risen in the last decades to reach concerning rates of nearly $20 \%$, which corresponds to over 340 million overweight children and adolescents aged 5 to 19 years in 2016. Childhood obesity is associated with breathing difficulties, an increased risk of fractures, hypertension, early markers of cardiovascular disease, insulin resistance, psychological effects and premature death and disability in adulthood [1].

The etiology of obesity is multifactorial and has been linked to genetic, metabolic, nutritional, activity, socioeconomic, psychological and prenatal factors [2].

Infants born large for gestational age (LGA) are more likely to be obese in childhood and adolescence [3-6]. These data, adjusted for ethnicity, sex and socioeconomic factors in different populations and settings, have recently been confirmed [7]. The reported risk ratios, adjusted for income, sex, ethnicity, parental marital status and parental physical activity levels, were highest for severe maternal obesity $(\mathrm{BMI}>35)$ followed by being born LGA and revealed being LGA to be an independent risk factor for overweight and obesity in adolescence and adulthood.

The developmental origin of an adult disease hypothesis suggests that large size at birth may predispose to early childhood obesity and metabolic syndrome and cardiovascular disease in later life $[8,9]$.

LGA is defined as a birth weight above the 90th percentile for the corresponding gestational age. Correspondingly, the LGA rate in a normal birth cohort is about $10 \%$. Risk factors closely associated with higher rates of LGA infants are maternal pre-gravid obesity, excessive gestational weight gain exceeding the recommendations of the Institute of Medicine (IOM) ( $\triangleright$ Table 1$)$, and diabetes in pregnancy [10].
- Table 1 Institute of Medicine weight gain recommendations for pregnancy (modified from the Institute of Medicine [10]).

\begin{tabular}{|l|l|l|}
\hline $\begin{array}{l}\text { Pre-pregnancy weight } \\
\text { category }\end{array}$ & $\begin{array}{l}\text { Body mass } \\
\text { index } \mathbf{( k g / \mathbf { m } ^ { 2 } )}\end{array}$ & $\begin{array}{l}\text { Recommended } \\
\text { range of total } \\
\text { weight } \mathbf{( k g )}\end{array}$ \\
\hline Underweight & Less than 18.5 & $12.5-18$ \\
\hline Normal weight & $18.5-24.9$ & $11.5-16$ \\
\hline Overweight & $25-29.9$ & $7-11.5$ \\
\hline Obese (includes all classes) & 30 and greater & $5-9$ \\
\hline
\end{tabular}

In this study, we aimed to evaluate the specific impact of these three risk factors on fetal macrosomia, evaluating what matters with regard to the risk of fetal overgrowth. We performed a retrospective cohort study of 12701 deliveries documented in our university hospital birth registry from 2003 to 2014.

\section{Materials and Methods}

\section{Cohort composition}

Data were based on the birth charts of 16292 deliveries recorded between 2003 and 2014 in the standardized nationally used perinatal documentation system of our university hospital. Pre-pregnancy body weight and height documented in the system were obtained from patients' maternity records. Body mass index and weight gain during pregnancy were calculated based on these data.

From this original cohort we included all women with singleton pregnancies who delivered after completing 37 weeks of gestation. Multiple pregnancies of one individual were not excluded, since repeated observations had no statistical effect. We excluded cases of fetal death and cases for which information about mater- 
nal pre-pregnancy weight, height and weight gain during pregnancy were lacking. 12701 cases were included in statistical analysis ( $\triangleright$ Fig. 1). The local ethics committee of Friedrich Schiller University, Jena, Germany approved this analysis (no. 5280-09/17).

Women were grouped into six weight categories (underweight [<18.5 kg/m²], normal weight [18.5-24.9 kg/m²], overweight [25-29.9 kg/m²], obesity class I [30-34.9 kg/m²], obesity class II [35-39.9 kg/m²] and obesity class III [>40 kg/m²]) according to the definitions of the World Health Organization [11].

We calculated gestational weight gain (GWG) as the difference between pre-pregnancy weight and the last documented weight in pregnancy. Women were grouped according to IOM criteria into "recommended weight gain" vs. "excessive weight gain" if their recommendations had been exceeded [10].

Primary outcome was the rate of LGA children in the different groups.

LGA and small for gestational age status (SGA) were defined using Voigt's percentiles for the body measurements of newborns which define LGA as above the 90th percentile and SGA newborns as below 10th percentile [12].

Secondary outcomes were the development of pre-eclampsia, blood loss $>1000 \mathrm{ml}$, induction of labor, mode of delivery, incidence of shoulder dystocia and admission of the newborn to the neonatal intensive care unit (NICU).

\section{Statistical analysis}

All patients who met the inclusion criteria were included in our analysis. No prior sample size estimation was performed. Categorical data were compared between groups by $x^{2}$ test. Since most of the continuous data were not normally distributed, we used the median for data presentation and description. Mann-Whitney Utest was performed to compare continuous data between groups. Adjusted odds ratio (ORs) for estimating the association between LGA, GWG, BMI and Diabetes were determined using multivariate logistic regression. ORs are presented with a $95 \%$ confidence interval $(\mathrm{Cl})$. The potential confounders "maternal age", "weeks of gestation", "parity" and "gender of the newborn" were included in the statistical analysis as covariates and are presented in footnotes. We did not find evidence for multicollinearity in our multivariate models. Generalized estimating equations were used to prove that there was no effect of repeated observations due to multiple deliveries by one individual. Statistical analysis was performed using SPSS 23.0. A p-value $<0.05$ was considered statistically significant.

\section{Results}

\section{Pregnancies resulting in LGA newborns are associated with higher rates of adverse pregnancy outcomes}

Cohort characteristics are shown in - Table 2. LGA pregnancies were associated with maternal risk factors such as overweight and obesity, diabetes and gestational weight gain. Furthermore LGA deliveries were significantly associated with higher rates of shoulder dystocia ( 2.1 vs. $0.3 \% ; p<0.01$ ), caesarean section (30 vs. $21 \% ; p<0.01)$, postpartum hemorrhage of more than $1000 \mathrm{ml}(6.25$ vs. $3.3 \% ; \mathrm{p}<0.01)$ and admission to the neonatal

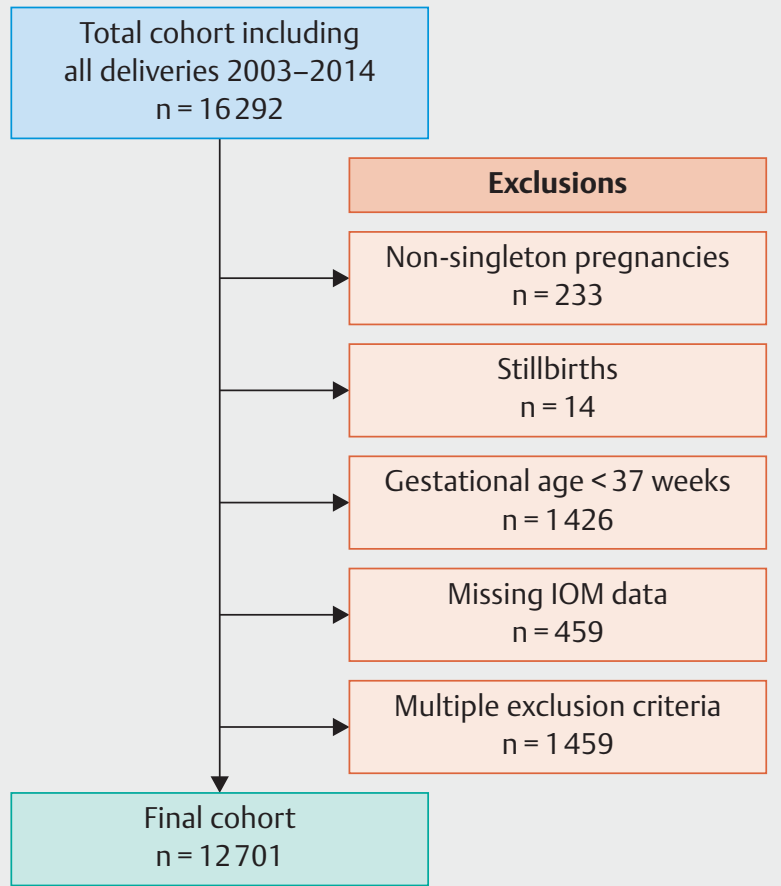

- Fig. 1 Cohort composition: the total cohort included 16292 deliveries between 2003 and 2014. Non-singleton pregnancies, stillbirths, deliveries before 37 weeks of gestation and cases where data on gestational weight gain were missing were excluded. A final cohort consisting of 12701 cases was analyzed.

intensive care unit ( 6 vs. 3.7\%; $p<0.01$ ). We did not find a difference with regard to the rates of pre-eclampsia ( 2.6 vs. $2.6 \%$; n.s.) and induction of birth (29.9 vs. $28.5 \%$ ) in the two groups ( $\triangleright$ Table 2).

\section{Diabetes in pregnancy, maternal BMI and excessive gestational weight gain are associated with increased risk of LGA birth}

Unadjusted analysis showed maternal class II and III obesity to be the major risk factor for delivery of a LGA newborn ( $\mathrm{II}^{\circ}$ vs. nonobesity $\mathrm{OR}=2.36$ [95\% Cl: $1.7-3.28] ; \mathrm{II}^{\circ} \mathrm{OR}=3.48$ [95\% Cl: 2.21-5.49]), followed by gestational weight gain exceeding IOM recommendations $(\mathrm{OR}=2.32$ [95\% Cl: 2.05-2.63]) and diabetes $(\mathrm{OR}=1.87$ [95\% Cl: 1.51-2.32]) ( Table 3).

\section{For underweight and normal weight women, the risk of LGA birth is strongly influenced by diabetes}

For women with gestational diabetes, the adjusted OR for giving birth to an LGA newborn was 11.818 (95\% Cl: 1.156-120.782) for underweight women, 1.564 (95\% Cl:1.013-2.415) for normal weight women, 1.242 (95\% Cl: 0.745-2.071) for overweight women, 0.859 (95\% Cl: 0.41-1.797) for women with class I obesity, 1.198 (95\% Cl: 0.463.3.097) for women with class II obesity, and 2.394 (95\% Cl: 0.485-11.825) for women with class III obesity ( $\bullet$ Table 4$)$. 
- Table 2 Cohort characteristics.

\begin{tabular}{|c|c|c|c|c|}
\hline & $\begin{array}{l}\text { Total cohort } \\
n=12701\end{array}$ & $\begin{array}{l}\text { LGA } \\
n=1191\end{array}$ & $\begin{array}{l}\text { AGA } \\
n=10362\end{array}$ & $\mathbf{p}^{*}$ \\
\hline LGA & $1191(9.4 \%)$ & & & \\
\hline Maternal age (years) & $29(26-33)$ & $30(27-34)$ & $29(26-33)$ & $<0.01$ \\
\hline Parity & $1(0-1)$ & $1(0-2)$ & $1(0-1)$ & $<0.01$ \\
\hline Diabetes & $671(5.3 \%)$ & $105(8.8 \%)$ & $531(5.1)$ & $<0.01$ \\
\hline $\mathrm{BMI}\left(\mathrm{kg} / \mathrm{m}^{2}\right)$ & $22.31(20.55-25.15)$ & $23.67(21.61-27.31)$ & $22.23(20.55-25.01)$ & $<0.01$ \\
\hline Underweight & $690(5.4 \%)$ & $21(1.8 \%)$ & $562(5.4 \%)$ & $<0.01$ \\
\hline Normal weight & $8747(68.9 \%)$ & $712(59.8 \%)$ & 7207 (69.6\%) & $<0.01$ \\
\hline Overweight & $2163(17 \%)$ & $273(22.9 \%)$ & $1743(16.8 \%)$ & $<0.01$ \\
\hline Obese $I^{\circ}$ & 735 (5.8\%) & $115(9.7 \%)$ & $573(5.5 \%)$ & $<0.01$ \\
\hline Obese $I^{\circ}$ & $260(2 \%)$ & $45(3.8 \%)$ & $204(2.0 \%)$ & $<0.01$ \\
\hline Obese $11 I^{\circ}$ & $106(0.8 \%)$ & $25(2.1 \%)$ & $73(0.7 \%)$ & $<0.01$ \\
\hline Below recommended weight gain & $2720(21.4 \%)$ & $150(12.6 \%)$ & $2184(21.1 \%)$ & $<0.01$ \\
\hline Recommended weight gain & $4263(33.6 \%)$ & $282(23.7 \%)$ & $3554(34.3 \%)$ & $<0.01$ \\
\hline Excessive weight gain & $5718(45 \%)$ & $759(63.7 \%)$ & $4624(44.6 \%)$ & $<0.01$ \\
\hline Weight gain in $\mathrm{kg}$ & $15(11-18)$ & $17(12-21)$ & $15(11-18)$ & $<0.01$ \\
\hline Pre-eclampsia & $345(2.7 \%)$ & $31(2.6 \%)$ & $270(2.6 \%)$ & n.s. \\
\hline Bleeding > $1000 \mathrm{ml}$ & $439(3.5 \%)$ & $74(6.2 \%)$ & $343(3.3 \%)$ & $<0.01$ \\
\hline Induction of birth & 3739 (29.4\%) & $356(29.9 \%)$ & 2957 (28.5\%) & n.s. \\
\hline Cesarean section & 2862 (22.5\%) & $357(30 \%)$ & $2181(21 \%)$ & $<0.01$ \\
\hline Instrumental delivery & 844 (6.6\%) & $57(4.8 \%)$ & 712 (6.9\%) & $<0.01$ \\
\hline Spontaneous birth & 8995 (70.8\%) & $777(65.2 \%)$ & 7469 (72.1\%) & $<0.01$ \\
\hline Shoulder dystocia & $53(0.4 \%)$ & $25(2.1 \%)$ & $28(0.3 \%)$ & $<0.01$ \\
\hline GA at delivery & $39.86(39.0-40.57)$ & $39.86(38.86-40.57)$ & $39.86(39-40.57)$ & n.s. \\
\hline Male sex & 6465 (50.9\%) & $614(51.6 \%)$ & $5279(50.9 \%)$ & n.s. \\
\hline Female sex & $6236(49.1 \%)$ & $577(48.4 \%)$ & 5083 (49.1\%) & n.s. \\
\hline Birth weight & $3430(3140-3730)$ & $4210(4050-4380)$ & $3430(3200-3660)$ & $<0.01$ \\
\hline NICU admission & $611(4.8 \%)$ & $72(6 \%)$ & $386(3.7 \%)$ & $<0.01$ \\
\hline LGA & 1191 (9.4\%) & & & \\
\hline SGA & $1142(9 \%)$ & & & \\
\hline AGA & $10362(81.6 \%)$ & & & \\
\hline $\begin{array}{l}\text { Data are presented as } n(\%) \text { or med } \\
\text { AGA: appropriate for gestational a } \\
{ }^{*} \text { significant difference between } A\end{array}$ & $\begin{array}{l}\text { nterquartile range unless ot } \\
\text { BMI: body mass index; LGA: }\end{array}$ & $\begin{array}{l}\text { se specified. } \\
\text { for gestational age baby }\end{array}$ & & \\
\hline
\end{tabular}

\section{Excessive gestational weight gain particularly affects the risk of LGA birth}

Adjusted analysis showed that the OR for LGA was 1.249 (95\% Cl: 1.018-1.533) for gestational weight gain exceeding IOM recommendations, 1.083 (95\% Cl: 1.066-1.099) for BMI and 1.315 (95\% Cl: 0.997-1.734) for diabetes, revealing LGA being the most relevant. Gestational weight gain which remained within the range recommended by the IOM reduced the risk of an LGA birth by $20 \%(\mathrm{OR}=0.801$ [95\% Cl: 0.652-0.982]). Overall, the risk of giving birth to an LGA infant increased by $6.9 \%$ with each $\mathrm{kg}$ weight gain ( $\triangleright$ Table 5 ).
For normal weight and overweight women, the risk of LGA birth increases significantly with each $\mathrm{kg}$ weight gain

When analysis focused on BMI classes, it was found that the risk of an LGA birth rose significantly in the group of normal weight women, increasing by $7.8 \%$ per $\mathrm{kg}$ weight gain $(\mathrm{OR}=1.078[95 \%$ $\mathrm{Cl}: 1.052-1.104])$ and by $5.8 \%$ in the group of overweight women $(\mathrm{OR}=1.058$ [95\% Cl: 1.026-1.09]) (• Fig. 2). 
- Table 3 Unadjusted odds ratios for large for gestational age.

\begin{tabular}{|c|c|c|c|c|c|c|c|c|c|c|c|}
\hline & \multirow[b]{2}{*}{$\begin{array}{l}\text { Total } \\
\text { cohort } \\
n=12701\end{array}$} & \multicolumn{2}{|l|}{ Diabetes } & \multicolumn{2}{|l|}{ GWG } & \multicolumn{6}{|c|}{ Pre-gravid BMI } \\
\hline & & $\begin{array}{l}\text { No } \\
\text { diabetes } \\
n=12030\end{array}$ & $\begin{array}{l}\text { Dia- } \\
\text { betes } \\
n=671\end{array}$ & $\begin{array}{l}\text { Recom- } \\
\text { mended } \\
\text { GWG } \\
n=6983\end{array}$ & $\begin{array}{l}\text { Excessive } \\
\text { GWG } \\
\mathbf{n = 5 7 1 8}\end{array}$ & $\begin{array}{l}\text { Under- } \\
\text { weight } \\
n=690\end{array}$ & $\begin{array}{l}\text { Normal } \\
\text { weight } \\
\mathbf{n}=\mathbf{8 7 4 7}\end{array}$ & $\begin{array}{l}\text { Over- } \\
\text { weight } \\
n=2163\end{array}$ & $\begin{array}{l}\text { Obese }^{\circ} \\
\mathrm{n}=735\end{array}$ & $\begin{array}{l}\text { Obese } I^{\circ} \\
n=260\end{array}$ & $\begin{array}{l}\text { Obese } I I I^{\circ} \\
n=106\end{array}$ \\
\hline & & $94.7 \%$ & $5.3 \%$ & $55 \%$ & $45 \%$ & $5.4 \%$ & $68.9 \%$ & $17 \%$ & $5.8 \%$ & $2.0 \%$ & $0.8 \%$ \\
\hline \multirow[t]{2}{*}{ LGA } & 1191 & 1086 & 105 & 432 & 759 & 21 & 712 & 273 & 115 & 45 & 25 \\
\hline & $9.4 \%$ & $9 \%$ & $15.7 \% *$ & $6.1 \%$ & $13.3 \% *$ & $3 \%$ & $8.1 \%$ & $12.6 \%$ & $15.7 \%$ & $17.3 \%$ & $23.6 \% *$ \\
\hline \multirow[t]{2}{*}{ Diabetes } & 671 & & & 349 & 322 & 14 & 290 & 187 & 94 & 61 & 25 \\
\hline & $5.3 \%$ & & & $4.9 \%$ & $5.6 \%$ & $2.0 \%$ & $3.3 \%$ & $8.6 \%$ & $12.8 \%$ & $23.5 \%$ & $23.6 \% *$ \\
\hline \multirow{2}{*}{$\begin{array}{l}\text { Excessive } \\
\text { weight gain }\end{array}$} & 5718 & 5396 & 322 & & & 161 & 3359 & 1503 & 512 & 136 & 47 \\
\hline & $45 \%$ & $44.9 \%$ & $48 \%$ & & & $23.3 \%$ & $38.4 \%$ & $69.5 \%$ & $69.7 \%$ & $52.3 \%$ & $44.3 \% *$ \\
\hline $\begin{array}{l}\text { Unadjusted } \\
\text { OR }(95 \% \mathrm{Cl})\end{array}$ & & \multicolumn{2}{|l|}{$\begin{array}{l}1.87^{* *} \\
(1.51-2.32)\end{array}$} & \multicolumn{2}{|c|}{$\begin{array}{l}2.32^{* *} \\
(2.05-2.63)\end{array}$} & $\begin{array}{l}0.35^{* *} \\
(0.23- \\
0.55)\end{array}$ & $\begin{array}{l}\text { Refer- } \\
\text { ence }\end{array}$ & $\begin{array}{l}1.63^{* *} \\
(1.41- \\
1.89)\end{array}$ & $\begin{array}{l}2.10^{* *} \\
(1.69- \\
2.59)\end{array}$ & $\begin{array}{l}2.36^{* *} \\
(1.70- \\
3.28)\end{array}$ & $\begin{array}{l}3.48^{* *} \\
(2.21- \\
5.49)\end{array}$ \\
\hline
\end{tabular}

* significant difference between subgroups of the three main groups Diabetes, GWG and Pre-gravid BMI, calculated using $x^{2}(p<0.05)$

** significant ORs for No diabetes vs. Diabetes, Recommended GWG vs. Excessive GWG and each BMI class compared to normal weight class BMI: body mass index; GWG: gestational weight gain; LGA: large for gestation age; OR: odds ratio

- Table 4 Risk of LGA birth for different BMI categories (overall and per kg weight gain).

\begin{tabular}{|c|c|c|c|c|c|}
\hline \multirow[t]{2}{*}{ BMI group $(n=9243$ ) } & & \multicolumn{2}{|c|}{ Adjusted ORs ${ }^{1}$ for LGA } & \multicolumn{2}{|c|}{ OR per kg GWG } \\
\hline & & ORs & $95 \% \mathrm{Cl}$ & ORs & $95 \% \mathrm{Cl}$ \\
\hline \multirow[t]{3}{*}{ Underweight ( $n=485$ ) } & Recommended GWG & 1.170 & $0.221-6.203$ & \multirow[t]{3}{*}{1.123} & \multirow[t]{3}{*}{$0.981-1.286$} \\
\hline & Excessive GWG & 0.854 & $0.161-4.529$ & & \\
\hline & Diabetes & $11.818^{*}$ & $1.156-120.782$ & & \\
\hline \multirow[t]{3}{*}{ Normal weight $(n=6281)$} & Recommended GWG & 0.763 & $0.580-1.004$ & \multirow[t]{3}{*}{$1.078^{*}$} & \multirow[t]{3}{*}{$1.052-1.104$} \\
\hline & Excessive GWG & 1.310 & $0.996-1.725$ & & \\
\hline & Diabetes & $1.564^{*}$ & $1.013-2.415$ & & \\
\hline \multirow[t]{3}{*}{ Overweight ( $n=1647$ ) } & Recommended GWG & 0.772 & $0.486-1.225$ & \multirow[t]{3}{*}{$1.058^{*}$} & \multirow[t]{3}{*}{$1.026-1.090$} \\
\hline & Excessive GWG & 1.296 & $0.816-2.058$ & & \\
\hline & Diabetes & 1.242 & $0.745-2.071$ & & \\
\hline \multirow[t]{3}{*}{ Obese $I^{\circ}(n=557)$} & Recommended GWG & 1.179 & $0.594-2.341$ & \multirow[t]{3}{*}{1.046} & \multirow[t]{3}{*}{$0.997-1.098$} \\
\hline & Excessive GWG & 0.848 & $0.427-1.684$ & & \\
\hline & Diabetes & 0.859 & $0.410-1.797$ & & \\
\hline \multirow[t]{3}{*}{ Obese $I^{\circ}(n=189)$} & Recommended GWG & 0.658 & $0.182-2.373$ & \multirow[t]{3}{*}{1.046} & \multirow[t]{3}{*}{$0.956-1.145$} \\
\hline & Excessive GWG & 1.521 & $0.421-5.488$ & & \\
\hline & Diabetes & 1.198 & $0.463-3.097$ & & \\
\hline \multirow[t]{3}{*}{ Obese $11 I^{\circ}(n=84)$} & Recommended GWG & 2.394 & $0.485-11.825$ & \multirow[t]{3}{*}{1.084} & \multirow[t]{3}{*}{$0.969-1.214$} \\
\hline & Excessive GWG & 0.418 & $0.085-2.064$ & & \\
\hline & Diabetes & 2.394 & $0.485-11.825$ & & \\
\hline \multicolumn{6}{|c|}{${ }^{1}$ Adjustments were made for maternal age, parity, gestational age and sex of newborn } \\
\hline \multirow{2}{*}{\multicolumn{6}{|c|}{$\begin{array}{l}\text { BMI: body mass index; Cl: confidence interval; GWG: gestational weight gain, LGA: large for gestational age } \\
{ }^{*} \mathrm{p}<0.05\end{array}$}} \\
\hline & & & & & \\
\hline \multicolumn{6}{|l|}{ Bold = significant results } \\
\hline
\end{tabular}




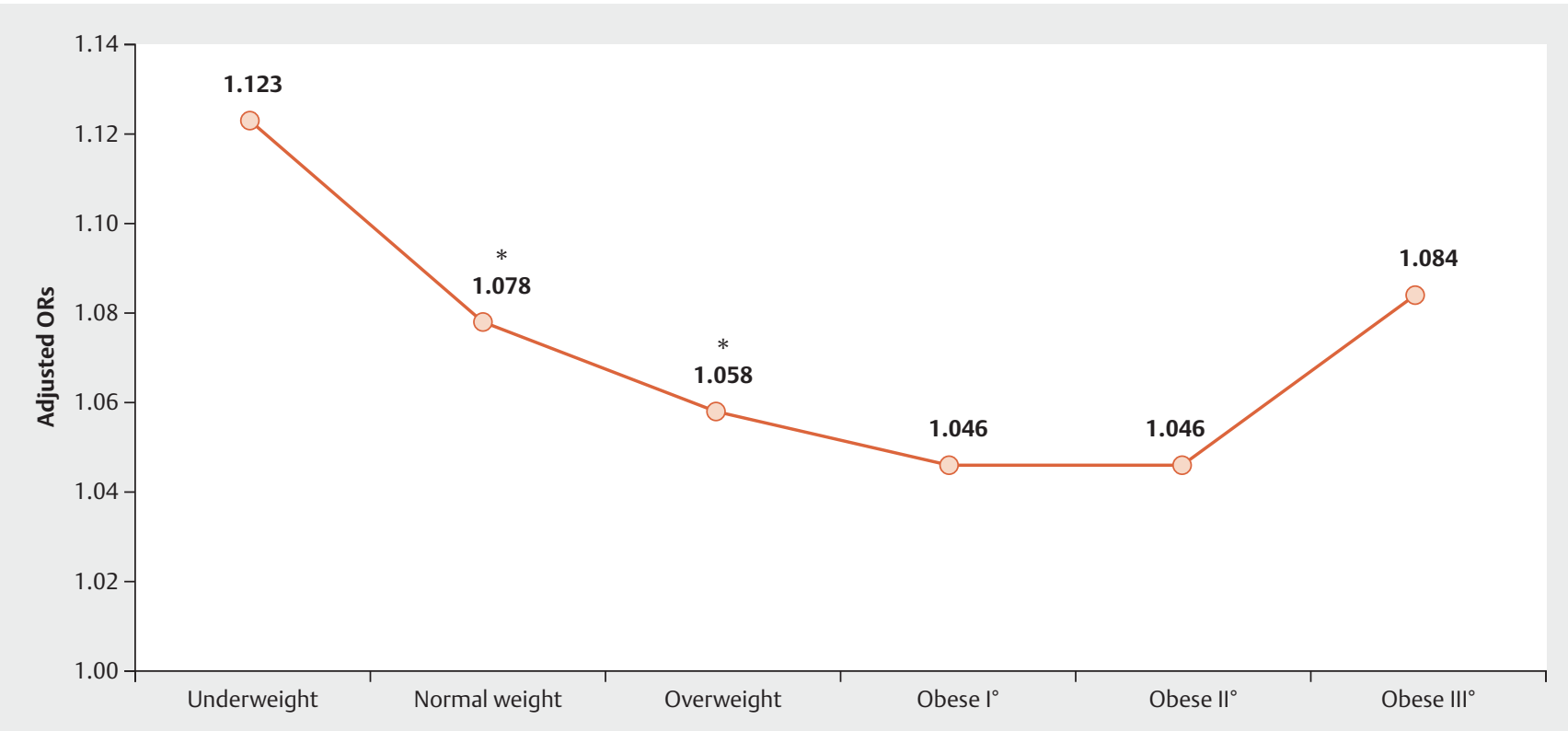

- Fig. 2 Adjusted ORs for LGA birth per kg weight gain. Adjusted ORs are shown for different classes of pre-gravid BMI. ORs showing a significant increase per $\mathrm{kg}$ weight gain are indicated with an asterisk $\left({ }^{*} \mathrm{p}<0.05\right)$.

- Table 5 Adjusted odds ratios for LGA birth.

\begin{tabular}{|c|c|c|c|}
\hline & & \multicolumn{2}{|c|}{ Adjusted ORs ${ }^{1}$ for LGA } \\
\hline & & OR & $\mathrm{Cl}$ \\
\hline \multirow[t]{5}{*}{ Total cohort $(n=9243)$} & Recommended GWG & $0.801^{*}$ & $0.652-0.982$ \\
\hline & Excessive GWG & $1.249^{*}$ & $1.018-1.533$ \\
\hline & $\mathrm{BMI}\left(\mathrm{kg} / \mathrm{m}^{2}\right)$ & $1.083^{*}$ & $1.066-1.099$ \\
\hline & Diabetes & 1.315 & $0.997-1.734$ \\
\hline & GWG per kg & $1.069^{*}$ & $1.052-1.087$ \\
\hline \multicolumn{4}{|c|}{${ }^{1}$ Adjustments were made for maternal age, parity, gestational age and sex of newborn } \\
\hline \multicolumn{4}{|c|}{ BMI: body mass index; CI: confidence interval; GWG: gestational weight gain; LGA: large for gestational age; OR: odds ratio } \\
\hline \multicolumn{4}{|l|}{${ }^{*} \mathrm{p}<0.05$} \\
\hline \multicolumn{4}{|l|}{ Bold = significant results } \\
\hline
\end{tabular}

\section{Discussion}

Pregnancies resulting in the birth of LGA infants are associated with adverse obstetric and neonatal outcomes ( $\triangleright$ Table 2 ). Our data showed that contributing risk factors for an LGA infant in our cohort were obesity prior to pregnancy, followed by gestational weight gain exceeding the IOM recommendations. Diabetes had a low, but still significant, impact ( $\vee$ Table 3 ). However, multivariate analysis of the effects on fetal LGA rates showed that ultimately the effect of diabetes was not significant and that gestational weight gain exceeding IOM recommendations had the most significant impact on the risk of giving birth to an LGA infant. Effectively, LGA rates increased by 6.9\% (OR: 1.069 [95\% Cl: $1.052-1.087])$ per $\mathrm{kg}$ weight gain. These findings are both re- markable and important, since gestational weight gain may be influenced by counseling and could be controlled during pregnancy.

This is particularly important as multivariate regression analysis for each BMI class revealed that women who are of normal weight or overweight but not obese before pregnancy have the highest risk of an LGA fetus when their gestational weight gain exceeds IOM recommendations ( $\vee$ Fig. 2 ). Our data also show that keeping maternal gestational weight gain within the recommended values decreased the risk of an LGA birth by nearly $20 \%$ (OR: 0.801 [95\% Cl: 0.652-0.982]). By comparison, excessive gestational weight gain increased the risk for LGA by $24.9 \%$ (OR 1.249 Cl 1.018-1.533) ( $\triangleright$ Table 5). In our data, diabetes only had a significant effect on LGA in the group of underweight women (OR: 11.818 [95\% Cl: 1.156-120.782]) and the group of normal weight 
women (OR: 1.564 [95\% Cl: 1.013-2.415) but not in the obese groups.

Our data are in accordance with the literature. A number of publications have reported that gestational weight gain is strongly associated with LGA rates [13-15]. Bloomberg and colleagues compared the influence of gestational weight gain in different classes of obese women. They also calculated odds ratios for LGA for women with excessive weight gain and reported an OR of 1.96 (1.80-2.14) for women with class I obesity, an OR of 1.87 (1.63-2.15) for women with class II obesity and an OR of 1.62 (1.29-2.03) for women with class III obesity. This effect within the different obesity classes could not be confirmed in our study, most probably because of different definitions of LGA. However, the authors concluded that obese women (class II and III) who lose weight during pregnancy appear to have a decreased risk of adverse obstetric outcomes including LGA births [16]. Kim et al. reported that maternal overweight and obesity, excessive gestational weight gain, and gestational diabetes were associated with LGA and concluded that preventing excessive gestational weight gain has the greatest potential to reduce the risk of LGA births. They also found considerably higher ORs for LGA for white women without diabetes who gained excessive weight, had a BMI of less than 25 (OR 15.1 [95\% Cl: 14.5-15.7]) or a BMI of 25 or greater (OR 23.8 [95\% Cl: 32.2-24.4]) compared to women with gestational diabetes mellitus and normal weight gain [17]. Zhao et al. showed that women with an abnormal pre-pregnancy body mass index and excessive gestational weight gain are at risk of adverse birth weight outcomes. In accordance with our findings, Zhao also concluded that gestational weight gain has a differential effect on the rates of adverse birth weight outcomes for women with different pre-pregnancy body mass index categories. They also reported the highest adjusted ORs for LGA and macrosomia (defined here as birth weight $>4000 \mathrm{~g}$ ) for normal weight women with a gestational weight gain which exceeded IOM recommendations. However, the authors did not adjust for gestational diabetes. They concluded that gestational weight gain is an independent predictor of LGA, a suggestion which has now been confirmed further by our study [18]. In a big Chinese cohort, Du and colleagues investigated the effects of pre-pregnancy BMI and gestational weight gain on neonatal birth weight and showed that in women with a lower pre-pregnancy BMI, gestational weight gain had a stronger positive effect on neonatal birth weight [19].

The importance of gestational weight gain as an independent risk factor for LGA was also emphasized by Kominiarek et al. Similar to our findings, they reported that $37 \%$ (38.4\% in our cohort) of normal weight women and $64 \%$ (69.5\% in our cohort) of overweight (but non-obese) women gained more weight during pregnancy than recommended by the IOM ( $\triangleright$ Table 3 ). The authors suggested that gestational weight gain could be a potentially modifiable risk factor for a number of adverse maternal and neonatal outcomes, as recent meta-analyses of randomized controlled trials have reported that diet or exercise interventions during pregnancy can help to reduce excessive gestational weight gain. But the authors noted that, so far, health behavior interventions to reduce gestational weight gain have not significantly improved maternal and neonatal outcomes and have only shown limited effectiveness among overweight and obese women and thus need to be improved [14]. Recommendations to reduce weight gain during pregnancy have been published. For obese women, it has already been shown that gestational weight gain below the national recommendations for obese mothers $(5-9 \mathrm{~kg})$ does not adversely affect fetal growth, gestational age at delivery, or mode of delivery [20]. Consequently, recommendations on gestational weight gain have been included in the updated version of the guidelines on the diagnosis, treatment and follow-up of gestational diabetes [21,22].

The obvious limitations of our study are its retrospective nature and the reliability of the electronic medical records, which resulted in a $10 \%$ exclusion rate because of missing data. Additionally, because of how the data was recorded in the database, the risk factor "diabetes" subsumed both gestational diabetes (GDM) and pre-existing diabetes. However, fewer than $2 \%$ of women who give birth in our university hospital suffer from pre-existing diabetes, which means that GDM is the predominant diabetic disorder of pregnant women in our study. Since information on glycemic control was not available for the non-diabetic cohort, we could not include this variable in our analysis. All women diagnosed with diabetes during pregnancy were diagnosed and treated according to the latest guidelines. After 2006, the diagnostic criteria for GDM used in our department strictly followed the IADPSG recommendations. General screening for GDM became a standard part of maternity care in 2012. These timings mean that our study may potentially have an additional bias due to the changes in diagnostic strategies. One of the strengths of our study is the large number of mother-infant dyads.

\section{Conclusion}

Being born large for gestational age has a lifelong impact on individual health. Multiple factors influence fetal birth weight. Overnutrition associated with excessive gestational weight gain and poorly controlled diabetes are risk factors which are possibly preventable. In our cohort, $38.4 \%$ of normal weight women and $69.5 \%$ ( $\triangleright$ Table 3 ) of overweight women had excessive weight gain in pregnancy, accounting for nearly $40 \%$ of the total cohort. These women are therefore a target cohort for intervention, as each additional prevented kilogram weight gain during pregnancy can reduce the risk for LGA by more than $5 \%$. Counseling on avoiding excessive gestational weight gain, dietary and exercise recommendations and information about the benefits which could be achieved by avoiding excessive weight gain should be mandatory, not only for obese women but also and especially for normal weight women and moderately overweight women. Thus, the implementation of structured counseling programs could have a significant effect on the increase in childhood obesity rates by reducing the risk factor of LGA birth.

\section{Conflict of Interest}

The authors declare that they have no conflict of interest. 


\section{References}

[1] WHO. Fact sheet No 311 - Obesity and overweight. 2018. Online: http://www.who.int/mediacentre/factsheets/fs311/en/; last access: 18.04.2018

[2] Han JC, Lawlor DA, Kimm SY. Childhood obesity. Lancet 2010; 375 : $1737-1748$

[3] Yu ZB, Han SP, Zhu GZ et al. Birth weight and subsequent risk of obesity: a systematic review and meta-analysis. Obes Rev 2011; 12: 525-542

[4] Lausten-Thomsen U, Nielsen TR, Thagaard IN et al. Neonatal anthropometrics and body composition in obese children investigated by dual energy X-ray absorptiometry. Eur J Pediatr 2014; 173: 623-627

[5] Sørensen HT, Sabroe S, Rothman KJ et al. Relation between weight and length at birth and body mass index in young adulthood: cohort study. BMJ 1997; 315: 1137

[6] Hermann GM, Dallas LM, Haskell SE et al. Neonatal macrosomia is an independent risk factor for adult metabolic syndrome. Neonatology 2010; 98: $238-244$

[7] Salahuddin M, Pérez A, Ranjit N et al. Predictors of Severe Obesity in Low-Income, Predominantly Hispanic/Latino Children: The Texas Childhood Obesity Research Demonstration Study. Prev Chronic Dis 2017; 14: E141

[8] Gluckman PD, Hanson MA, Cooper C et al. Effect of in utero and early-life conditions on adult health and disease. N Engl J Med 2008; 359: 61-73

[9] Simmons R. Perinatal programming of obesity. Semin Perinatol 2008; 32: $371-374$

[10] Institute of Medicine, National Research Council. Weight Gain during Pregnancy: Reexamining the Guidelines. Washington, DC: The National Academies Press; 2009

[11] WHO. Body mass index - BMI. 2017. Online: http://www.euro.who.int/ en/health-topics/disease-prevention/nutrition/a-healthy-lifestyle/bodymass-index-bmi; last access: 26.09.2017
[12] Voigt M, Fusch C, Olbertz D et al. Analysis of the neonatal collective in the Federal Republic of Germany 12th report. Presentation of detailed percentiles for the body measurement of newborns. Geburtsh Frauenheilk 2006; 66: 956-970

[13] Goldstein RF, Abell SK, Ranasinha S et al. Association of gestational weight gain with maternal and infant outcomes: A systematic review and meta-analysis. JAMA 2017; 317: 2207-2225

[14] Kominiarek MA, Peaceman AM. Gestational weight gain. Am J Obstet Gynecol 2017; 217: 642-651

[15] Yan J. Maternal pre-pregnancy BMI, gestational weight gain, and infant birth weight: A within-family analysis in the United States. Econ Hum Biol 2015; 18: 1-12

[16] Blomberg M. Maternal and neonatal outcomes among obese women with weight gain below the new Institute of Medicine recommendations. Obstet Gynecol 2011; 117: 1065-1070

[17] Kim SY, Sharma AJ, Sappenfield W et al. Association of maternal body mass index, excessive weight gain, and gestational diabetes mellitus with large-for-gestational-age births. Obstet Gynecol 2014; 123: 737744

[18] Zhao R, Xu L, Wu ML et al. Maternal pre-pregnancy body mass index, gestational weight gain influence birth weight. Women Birth 2018; 31: e20-e25

[19] Du MK, Ge LY, Zhou ML et al. Effects of pre-pregnancy body mass index and gestational weight gain on neonatal birth weight. J Zhejiang Univ Sci B 2017; 18: 263-271

[20] Bodnar LM, Pugh S], Lash TL et al. Low Gestational Weight Gain and Risk of Adverse Perinatal Outcomes in Obese and Severely Obese Women. Epidemiology 2016; 27: 894-902

[21] Schafer-Graf UM. Gestational Diabetes - Major New Clinically Relevant Aspects. Geburtsh Frauenheilk 2018; 78: 977-983

[22] Schäfer-Graf UM, Gembruch U, Kainer F et al. Gestational Diabetes Mellitus (GDM) - Diagnosis, Treatment and Follow-Up. Guideline of the DDG and DGGG (S3 Level, AWMF Registry Number 057/008, February 2018). Geburtsh Frauenheilk 2018; 78: 1219-1231. doi:10.1055/a-0659-2596 